\title{
The Role of Diabetes Mellitus in the Clinical Presentation and Prognosis of Bell Palsy
}

\author{
Maria Riga, MD, George Kefalidis, MD, PhD, and Vasilios Danielides, MD
}

Background: Bell palsy is considered to be an entrapment neuropathy resulting from inflammation, edema, and strangulation. Diabetes, hypertension, and hypercholesterolemia have all been related to microangiopathies. However, the relationship between the frequency, severity, and recovery course of Bell palsy in patients with these pathologies is a matter of controversy.

Methods: Fifty-six patients with Bell palsy were evaluated according to the House-Brackmann grading system a few days after the onset of the disease and 6 months later and correlated to their hypertension, hypercholesterolemia, and diabetes records. Diabetes was evaluated by the use of serum glycosylated hemoglobin (HbA1c).

Results: The 20 patients with abnormal HbA1c values were more frequently diagnosed with Bell palsy of grade V/VI $(P=.008$; odds ratio, 4.7; 95\% CI, 1.4-15.2). However, their House-Brackmann scores were not found to be worse at the 6-month follow-up visit $(P=.9)$. No correlations were found for hypertension and hypercholesterolemia.

Conclusions: A relationship between the severity of Bell palsy and abnormal HbA1c values seems to be demonstrated. However, the prognosis of these patients does not seem to be worse because at the 6-month follow-up visit they present similar scores to nondiabetic patients. (J Am Board Fam Med 2012;25:819-826.)

Keywords: Bell Palsy, Diabetes Mellitus, Neurology, Otolaryngology

Bell palsy is defined as a sudden paralysis/paresis of all muscle groups on one side of the face that cannot be attributed to any central nervous system, ear, or cerebellopontine angle disease. Approximately 1 in 65 people may experience such a condition in their lifetime. Almost 2 centuries after its first description by Sir Charles Bell, the etiology and prognostic factors of Bell palsy remain unclear. Microcirculatory failure of the vasa nervosum, ischemic neuropathy, and infectious, genetic, and immunologic causes have been hypothesized. ${ }^{1-3}$ The long-term prognosis of this condition is inevitably a major concern for both patients and physicians.

This article was externally peer reviewed.

Submitted 14 March 2012; revised 9 July 2012; accepted 2 August 2012.

From the Department of Otorhinolaryngology, Head and Neck Surgery, University Hospital of Alexandroupolis, Democritus University of Thrace, Greece (MR, VD); and Democritus University of Thrace, Greece (GK).

Funding: none.

Conflict of interest: none declared.

Corresponding author: Maria Riga, MD, 35 Leoforos Makris, Nea Chili, 68100, Alexandroupolis, Greece (E-mail: mariariga@hotmail.com).
Diabetes, hypertension, and hypercholesterolemia all have been correlated with microangiopathy, which, according to the theory of microcirculatory failure of the vasa nervosum, is a potential causative and poor prognostic factor in Bell palsy. To date, the respective literature reports are quite controversial. ${ }^{4-7}$ The facial nerve represents a unique case where a cranial nerve is confined within a bony canal, known as the fallopian canal, and Bell palsy represents a unique case of nerve entrapment in a bony canal. Therefore, the study of the factors affecting the clinical presentation and prognosis of Bell palsy constitutes a challenge in the pathophysiology of peripheral nerves.

The aim of this study was to demonstrate any correlation between diabetes, hypertension, or hypercholesterolemia and the severity of Bell palsy at its onset and after a 6-month interval. Contrary to previous reports, the correlation between diabetes and Bell palsy was not investigated by the use of fasting plasma glucose (FPG) but through serum glycosylated hemoglobin (HbA1c) levels, which are thought to state a brief history of the patients' 
glycemic control over the last 2 to 3 months unaffected by diet, insulin, other hypoglycemic drugs or exercise. ${ }^{8,9}$ The possible pathophysiologic mechanisms explaining the results of this study as well as the clinical implications of the findings are discussed.

\section{Patients and Methods}

Fifty-six consecutive patients (28 women, 28 men) who presented with Bell palsy to the emergency otorhinolaryngology department of a tertiary hospital over 3 years were included in the study. The patients' ages ranged from 21 to 82 years (mean \pm standard deviation [SD], $54 \pm 31.7$ years). Children were not included in the study. According to the House-Brackmann (H-B) grading system, this population presented the following distribution 3 to 4 days after the initiation of the palsy. ${ }^{9}$ Three patients were diagnosed with grade III, 27 with grade IV, 7 with grade V, and 19 with grade VI. After a 6-month follow-up, complete recovery was achieved in $48 \mathrm{pa}-$ tients. Three patients still presented a grade III and 5 patients a grade II paresis. Bell palsy of grade $\mathrm{V}$ and VI was characterized as "severe." All 56 patients received the same therapeutic protocol, which included intravenous administration of prednisolone $(100 \mathrm{mg}$ on day $1 ; 75 \mathrm{mg}$ on days 2, 3, and 4; $50 \mathrm{mg}$ days 5 and 6 ; and $25 \mathrm{mg}$ on days 7 and 8 of admission) and acyclovir $500 \mathrm{mg}$ intravenous thrice daily. Serum glucose in diabetic patients was monitored thrice daily with finger prick testing, and appropriate treatment was administered according to the instructions of their treating physician. Recurrence episodes were noted in 3 patients.

The diagnosis of hypertension and hypercholesterolemia was based on the medical history and records of the patients. Diabetes was defined according to the 1997 American Diabetes Association Expert Committee criteria: FPG $\geq 7.00 \mathrm{mmol} / \mathrm{L}$ or treatment with oral antidiabetic drugs or insulin. Abnormal values of serum $\mathrm{HbAlc}$ were used as an indicator of an index of mean plasma glucose over the preceding weeks to months. ${ }^{10,11}$ HbAlc levels of $6.5 \%$ or higher were considered abnormal and, as far as string variables were concerned, patients were included in the "diabetic" group. Patients receiving oral antidiabetic drugs or insulin who had normal HbA1c values were excluded from the study because diabetic polyneuropathy seems to be highly dependable on glycemic control. Even short-term improvements in glycemic control and serum tri- glyceride levels have been reported to have an independent, additive, and durable effect on restoration of nerve function in patients with mild to moderate diabetic sensorimotor polyneuropathy. ${ }^{12}$

\section{Statistical Analysis}

Statistical analysis was conducted with SPSS software version 17.0 (SPSS, Inc, Chicago, IL). Statistical comparisons between patient and control groups for string values (diabetic or nondiabetic, with or without a history of hypertension or hypercholesterolemia) were performed using Pearson $\chi^{2}$ test. Colinearity diagnostics for numerical values (HbA1c, cholesterol, low-density lipoproteins [LDL], high-density lipoproteins [HDL], and triglycerides) were performed using a variation infiltration factor. Correlations between numerical values and $\mathrm{H}-\mathrm{B}$ scores at admission and the 6-month follow-up visit were calculated using the Kruskal-Wallis nonparametric test for $\mathrm{k}$ independent variables (the Monte Carlo technique). Significance was attributed at $P \leq .05$.

\section{Ethical Considerations}

The study was performed in accordance with the Declaration of Helsinki and was approved by the institutional ethical committee.

\section{Results}

In the population of this study, HbA1c ranged $3.3 \%$ to $9.8 \%$ (mean $\pm \mathrm{SD}, 5.8 \pm 1.4$ ), the values of serum cholesterol ranged from 11 to $395 \mathrm{mg} / \mathrm{dL}$ $(216.3 \pm 60.6)$, the values of LDLs ranged from 57.8 to $270.6 \mathrm{mg} / \mathrm{dL}(150.4 \pm 43.5)$, the values of HDLs ranged from 31 to $92 \mathrm{mg} / \mathrm{dL}(53.7 \pm 12)$, and the values of triglycerides ranged from 42 to $609 \mathrm{mg} / \mathrm{dL}(165 \pm 87.4)$.

Among the 56 patients in this study, 20 patients presented with abnormal values of HbA1c, 26 with a history of hypertension, and 16 with a history of hypercholesterolemia. The distribution of H-B classification of these groups of patients at admission is presented in Table 1. After statistical analysis (Pearson $\chi^{2}$ test, cross-tabulation), it was demonstrated that severe Bell palsy of grade V and VI was significantly more frequent among patients with abnormal HbA1c values $(P=.008)$. Among the 20 patients who presented with abnormal HbA1c values, 14 patients were diagnosed with Bell palsy of grade $\mathrm{V}$ and VI, whereas only 6 were diagnosed with grade IV or less. The possibility of 
Table 1. Correlation of the Severity of Bell Palsy (House-Brackmann Classification) with the Patients' History of Hypertension and Hypercholesterolemia and with Abnormal Values of Glycosylated Hemoglobin (HbA1c)

\begin{tabular}{ccccc}
\hline House-Brackmann Classification & Total & HbAlc & Hypertension & Hypercholesterolemia \\
\hline 3 & 3 & - & 1 & 1 \\
4 & 27 & 6 & 10 & 6 \\
5 & 7 & 3 & 4 & 2 \\
6 & 19 & 11 & 26 & 7 \\
total & 56 & 20 & .5 & 16 \\
$P^{*}$ & & $\mathbf{. 0 4 5}$ & & .7 \\
\hline
\end{tabular}

Bold values are statistically significant. Pearson $\chi^{2}$ test.

patients with abnormal values of HbA1c to present with a Bell palsy of grade V and VI was 4.7 times higher than for patients with normal HbA1c values (95\% confidence interval, 1.4-15.2) (Table 2).

However, hypertension and hypercholesterolemia were not found to be correlated with the severity of Bell palsy. Among the 56 patients in this study, 26 were diagnosed with hypertension and 16 with hypercholesterolemia. Among the 26 patients with a history of high blood pressure, 15 were diagnosed with Bell palsy grade V and VI and 11 were diagnosed with grade IV or less (Pearson $\chi^{2}$ test, $P=.1$ ). Similarly, among the 16 patients with a history of hypercholesterolemia, 9 were diagnosed with Bell palsy grade V and VI and 7 with grade IV or less $(P=.4)$ (Table 2$)$.

A variation infiltration factor was marginally $<2$, indicating an absence of colinearity for numerical values (HbA1c, cholesterol, LDL, HDL and triglycerides). H-B scores at admission were significantly correlated with numerical $\mathrm{HbAlc}$ values (Kruskal-Wallis test, $P=.016$ ). None of the other measured values were significantly correlated to H-B scores at admission (cholesterol, $P=.4$; LDL, $P=.06$; HDL, $P=.5$; and triglycerides, $P=.7$ ).

Nevertheless, it is noteworthy that patients with abnormal HbA1c values were not found to have a worse prognosis at the 6-month follow-up visit. Six months after hospitalization, 17 of the 20 patients with abnormal HbA1c values had fully recovered (Table 3) (Pearson $\chi^{2}$ test, $P=.9$ ). The same limited prognostic value seems to apply for hypertension and hypercholesterolemia as well. Among the 26 patients with history of high blood pressure, 22 presented themselves fully recovered 6 months later, whereas a full recovery was noted for 13 of the 16 patients with a history of hypercholesterolemia ( $P=.8$ and $P=.5$, respectively) (Tables 3 and 4). Consistent with the above, H-B scores at the 6-month follow-up visit were not significantly correlated to any of the measured numerical values (Kruskal-Wallis test: HbA1c, $P=.7$; cholesterol, $P=.2$; LDL, $P=.06$; HDL, $P=.7$; and triglycerides, $P=.4$ ). The population of this study is presented in detail in Table 5 .

\section{Discussion}

The frequency of Bell palsy in diabetic patients is a matter of controversy. According to most authors, the percentage of diabetics among patients with Bell palsy is not higher than in the general population, ${ }^{7,13-15}$ although there are some reports that refer to Bell palsy as occurring more commonly in

Table 2. Correlation of the Severity of Bell Palsy (House-Brackmann Classification) with the Patients' History of Hypertension and Hypercholesterolemia and with Abnormal Values of Glycosylated Hemoglobin (HbA1c)

\begin{tabular}{|c|c|c|c|c|}
\hline House-Brackmann Classification & HbA1c & Hyper-tension & Hyper-cholesterolemia & Total \\
\hline $5-6$ & 14 & 15 & 9 & 26 \\
\hline$\leq 4$ & 6 & 11 & 7 & 30 \\
\hline Total & 20 & 26 & 16 & 56 \\
\hline$P^{*}$ & .008 & .1 & .4 & \\
\hline Odds ratio (95\% confidence interval) & $4.7(1.4-15.2)$ & $2.3(0.8-6.9)$ & $1.7(0.5-5.6)$ & \\
\hline
\end{tabular}

Bold values are statistically significant. Pearson $\chi^{2}$ test. 
Table 3. Correlation of the Severity of Bell Palsy (House-Brackmann Classification) with the Patients' History of Hypertension and Hypercholesterolemia and with Abnormal Values of Glycosylated Hemoglobin (HbA1c) at Follow-up Visit, 6 Months Later

\begin{tabular}{|c|c|c|c|c|}
\hline House-Brackmann Classification & Total & HbA1c & Hypertension & Hypercholesterolemia \\
\hline 1 & 48 & 17 & 22 & 13 \\
\hline 2 & 5 & 1 & 2 & 2 \\
\hline 3 & 3 & 2 & 2 & 1 \\
\hline $4-6$ & 0 & 0 & 0 & 0 \\
\hline Total & 56 & 20 & 26 & 16 \\
\hline$P^{*}$ & & .4 & .7 & .8 \\
\hline
\end{tabular}

Pearson $\chi^{2}$ test.

patients with diabetes, or even prediabetes, and in pregnant women. ${ }^{16-18}$ Regarding the severity of the palsy, 2 previous studies have failed to establish any correlation between diabetes mellitus or hypertension and the severity of Bell palsy. ${ }^{4,5}$ Kudoh et $\mathrm{al}^{19}$ reported that noninsulin-dependent diabetes mellitus (NIDDM) or hypertension does not seem to have any significant effect on palsy scores and electroneuronography results, although patients with both NIDDM and hypertension are slow to recover. Previous reports also have shown that NIDDM and hypertension can influence the recovery of palsy, although the prognosis of Bell palsy associated with NIDDM alone is still a matter of controversy. ${ }^{6}$

It is noteworthy that most of the relevant literature is quite old. The assessment of any correlation between Bell palsy and diabetes mellitus or hypertension with the use of contemporary demographic data and modern diagnostic or therapeutic means is limited. To date, most studies attempting to establish a relationship between diabetes and Bell palsy have used FPG and 2-hour plasma glucose after an oral glucose tolerance test to identify diabetic patients or subjects at a high risk of diabetes. ${ }^{20}$ However, the oral glucose tolerance test is not common in clinical practice because it is time consuming, costly, and less reproducible than measurement of FPG. ${ }^{21}$ The importance of HbAlc levels lies in the fact that it states a brief history of the patients' glycemic control over the last 2 to 3 months because an erythrocyte's life span averages 120 days. FPG alone is not a sufficient test to diagnose a patient as diabetic because there is a possibility of giving false results. However, once glycosylation occurs, the concentration of HbA1c does not vary day to day and is unaffected by diet, insulin, other hypoglycemic drugs, or exercise on the day of investigation contrary to the estimation of blood glucose. ${ }^{8,11} \mathrm{HbA1c}$ is correlated with FPG and 2-hour plasma glucose. HbA1c is more reproducible than FPG, and within-subject coefficients of variation are 1.7 and $5.7 \%$, respectively. ${ }^{22-26}$ The use of abnormal HbAlc values as the criterion for diagnosing diabetic patients and including them in our "diabetic" group may explain the different results reported by this study, which seem to point

Table 4. Correlation of the Severity of Bell's Palsy (House-Brackmann Classification) with the Patients' History of Hypertension and Hypercholesterolemia and with Abnormal Values of Glycosylated Haemoglobin (HbA1c) at Follow-up Visit, 6 Months Later

\begin{tabular}{|c|c|c|c|c|}
\hline House-Brackmann Classification & HbAlc & Hypertension & Hypercholesterolemia & Total \\
\hline 1 & 17 & 22 & 13 & 48 \\
\hline$\geq 2$ & 3 & 4 & 3 & 8 \\
\hline Total & 20 & 26 & 16 & \\
\hline$P^{*}$ & .9 & .8 & .5 & \\
\hline Odds ratio ( $95 \%$ confidence interval) & $1.1(0.2-5.1)$ & $1.2(0.3-5.3)$ & $1.6(0.3-7.7)$ & \\
\hline
\end{tabular}

Pearson $\chi^{2}$ test. 
Table 5. Demographic Data of the Patients Included in the Study

\begin{tabular}{|c|c|c|c|c|c|c|c|c|}
\hline Patient & Sex & $\begin{array}{l}\text { H-B Admission } \\
\text { (Grade) }\end{array}$ & $\begin{array}{l}\text { H-B Follow-up } \\
\text { (Grade) }\end{array}$ & HbAlc (\%) & $\begin{array}{l}\text { Cholesterol } \\
(\mathrm{mg} / \mathrm{dL})\end{array}$ & $\begin{array}{c}\mathrm{LDL} \\
(\mathrm{mg} / \mathrm{dL})\end{array}$ & $\begin{array}{c}\mathrm{HDL} \\
(\mathrm{mg} / \mathrm{dL})\end{array}$ & $\begin{array}{l}\text { Triglycerides } \\
\text { (mg/dL) }\end{array}$ \\
\hline 1 & 1 & 5 & 1 & 4.9 & 246 & 145 & 56 & 185 \\
\hline 2 & 0 & 6 & 2 & 6.8 & 282 & 202 & 67 & 65 \\
\hline 3 & 1 & 4 & 1 & 5.5 & 220 & 135 & 52 & 165 \\
\hline 4 & 1 & 6 & 1 & 7.9 & 289 & 203 & 35 & 199 \\
\hline 5 & 0 & 4 & 1 & 6.1 & 177 & 98.6 & 43 & 177 \\
\hline 6 & 1 & 5 & 1 & 5.3 & 220 & 133.4 & 63 & 118 \\
\hline 7 & 0 & 4 & 1 & 4.5 & 275 & 200.8 & 58 & 81 \\
\hline 8 & 0 & 6 & 2 & 4.6 & 268 & 199 & 49 & 155 \\
\hline 9 & 0 & 4 & 1 & 4.1 & 222 & 149 & 45 & 155 \\
\hline 10 & 0 & 5 & 1 & 6.8 & 197 & 123.8 & 58 & 76 \\
\hline 11 & 0 & 4 & 1 & 6.9 & 181 & 114.2 & 47 & 99 \\
\hline 12 & 1 & 6 & 3 & 4.8 & 296 & 205.2 & 60 & 154 \\
\hline 13 & 0 & 4 & 1 & 5.5 & 169 & 73.4 & 54 & 208 \\
\hline 14 & 0 & 3 & 1 & 3.5 & 175 & 104.8 & 54 & 81 \\
\hline 15 & 0 & 4 & 1 & 8.9 & 258 & 147 & 68 & 215 \\
\hline 16 & 0 & 5 & 1 & 4.4 & 151 & 57.8 & 74 & 96 \\
\hline 17 & 0 & 6 & 1 & 7.4 & 190 & 128.8 & 43 & 91 \\
\hline 18 & 1 & 4 & 1 & 6.1 & 209 & 122.8 & 61 & 126 \\
\hline 19 & 1 & 4 & 1 & 4.3 & 199 & 165 & 56 & 156 \\
\hline 20 & 0 & 3 & 1 & 4.6 & 253 & 133.4 & 59 & 303 \\
\hline 21 & 1 & 6 & 1 & 7.1 & 268 & 187 & 55 & 185 \\
\hline 22 & 0 & 6 & 2 & 5.6 & 245 & 186 & 56 & 155 \\
\hline 23 & 1 & 5 & 1 & 6.8 & 327 & 216.8 & 71 & 196 \\
\hline 24 & 1 & 4 & 1 & 4.6 & 174 & 100 & 92 & 196 \\
\hline 25 & 0 & 4 & 1 & 6.5 & 241 & 176 & 63 & 319 \\
\hline 26 & 1 & 4 & 1 & 4.5 & 150 & 123 & 65 & 120 \\
\hline 27 & 0 & 6 & 1 & 5.24 & 199 & 128.2 & 38 & 134 \\
\hline 28 & 0 & 4 & 1 & 9.5 & 252 & 99.2 & 31 & 609 \\
\hline 29 & 1 & 4 & 1 & 5.5 & 242 & 156.4 & 62 & 118 \\
\hline 30 & 0 & 4 & 1 & 3.28 & 234 & 155.8 & 66 & 155.8 \\
\hline 31 & 0 & 4 & 1 & 4.3 & 215 & 138 & 55 & 110 \\
\hline 32 & 1 & 4 & 1 & 5.5 & 245 & 167 & 56 & 145 \\
\hline 33 & 1 & 6 & 1 & 7.5 & 235 & 163 & 67 & 150 \\
\hline 34 & 1 & 4 & 1 & 5.6 & 185 & 97.8 & 65 & 111 \\
\hline 35 & 1 & 6 & 1 & 5 & 118 & 76 & 36 & 200 \\
\hline 36 & 0 & 6 & 2 & 6.3 & 193 & 137.71 & 55 & 145 \\
\hline 37 & 1 & 5 & 1 & 7.8 & 201 & 178 & 32 & 291 \\
\hline 38 & 1 & 4 & 1 & 4.6 & 224 & 146 & 65 & 65 \\
\hline 39 & 1 & 4 & 1 & 5.5 & 207 & 131.2 & 49 & 134 \\
\hline 40 & 1 & 4 & 1 & 4.8 & 154 & 83.2 & 45 & 129 \\
\hline 41 & 0 & 4 & 1 & 6.8 & 246 & 158 & 59 & 145 \\
\hline 42 & 0 & 6 & 2 & 4.8 & 219 & 167 & 59 & 119.8 \\
\hline 43 & 0 & 5 & 1 & 4.8 & 178 & 126.8 & 34 & 86 \\
\hline 44 & 1 & 4 & 1 & 4.5 & 208 & 156 & 52 & 85 \\
\hline 45 & 0 & 6 & 1 & 7.2 & 182 & 127.6 & 46 & 42 \\
\hline 46 & 0 & 6 & 1 & 6.8 & 11 & 151.2 & 39 & 219 \\
\hline 47 & 1 & 4 & 1 & 5.3 & 35 & 179 & 45 & 199 \\
\hline 48 & 1 & 6 & 1 & 9.8 & 395 & 270.6 & 65 & 297 \\
\hline 49 & 0 & 3 & 1 & 6.1 & 288 & 242 & 45 & 205 \\
\hline
\end{tabular}


Table 5. Continued

\begin{tabular}{ccccccccc}
\hline Patient & Sex & H-B Admission & H-B Follow-up & HbAlc $(\%)$ & $\begin{array}{c}\text { Cholesterol } \\
(\mathrm{mg} / \mathrm{dL})\end{array}$ & $\begin{array}{c}\text { LDL } \\
(\mathrm{mg} / \mathrm{dL})\end{array}$ & $\begin{array}{c}\text { HDL } \\
(\mathrm{mg} / \mathrm{dL})\end{array}$ & $\begin{array}{c}\text { Triglycerides } \\
(\mathrm{mg} / \mathrm{dL})\end{array}$ \\
\hline 50 & 0 & 4 & 1 & 4.8 & 192 & 147 & 34 & 55 \\
51 & 1 & 4 & 1 & 5.6 & 202 & 102.2 & 55 & 224 \\
52 & 1 & 6 & 3 & 7.1 & 216 & 135.8 & 36 & 221 \\
53 & 1 & 6 & 1 & 8.4 & 286 & 233 & 52 & 250 \\
54 & 1 & 6 & 3 & 6.9 & 235 & 206 & 53 & 183 \\
55 & 1 & 4 & 1 & 6 & 225 & 178 & 65 & 175 \\
56 & 0 & 6 & 1 & 5.9 & 212 & 156 & 45 & 165 \\
\hline
\end{tabular}

0, male; 1, female; H-B, House-Brackmann classification; HbA1c, glycosylated hemoglobin; LDL, low-density lipoprotein; HDL, high-density lipoprotein.

out a relationship between the severity of Bell palsy and abnormal glucose metabolism.

Bell palsy is considered to be an entrapment neuropathy resulting from inflammation, edema, and strangulation of the facial nerve within the osseous fallopian canal. Part of the dysfunction is, therefore, attributed to vascular congestion with ischemia or impairment of axonoplasmic flow. This conclusion has been based on previous findings in perioperative and magnetic resonance imaging studies, as well as the significantly better outcome after corticosteroid administration compared with placebo. ${ }^{27-30}$ Peripheral nerves are vascularized by a longitudinal network of vessels linked by many anastomoses between the longitudinal vessels, allowing the blood flow to continue when individual segmental arteries are occluded. This is also the reason why a major impairment in blood flow is necessary to produce experimental ischemic nerve lesions. $^{31}$ In diabetic patients, there is chronic nerve ischemia due to reduction in endoneurial oxygen, reduced nerve blood flow, and epineurial arteriovenous shunting. ${ }^{14,32,33}$ The abnormalities of endoneurial vessels, such as basal membrane thickening and endothelial cell proliferation, contribute to this effect and have been described extensively. ${ }^{34-36}$ The microangiopathy may also be a compensatory response to endoneurial ischemia/ hypoxia induced by chronic hyperinsulinemia. ${ }^{37}$ Moreover, hyperglycemia causes direct nerve injury by several mechanisms including increased oxidative stress, accumulation of advanced glycation endoproducts, impaired axonal transport, and impaired flow through the polyol pathway. ${ }^{38}$ Embryonic rat dorsal root ganglionic cell cultures demonstrate apoptotic cell death and reduced neurite outgrowth when exposed to acute hyperglycemia. ${ }^{39}$
Pre-existing nerve ischemia and injury, as well as abnormalities of endoneurial and epineurial vessels could, therefore, be a possible reason for the worse $\mathrm{H}-\mathrm{B}$ scores noted in diabetic patients at the time of their presentation to the emergency department.

On the other hand, this pre-existing nerve ischemia may act as a preconditioning nerve lesion, which may explain the good recovery of diabetic patients, who, although they first appear with worse H-B scores, manage to present themselves at the 6-month follow-up visit with scores similar to nondiabetic patients. Studies of axonal regeneration in the sciatic nerve have shown that a conditioning lesion of the tibial nerve (a branch of the sciatic nerve) made 2 weeks before a sciatic nerve injury causes a significant increase in axon outgrowth. ${ }^{40,41}$ Further work has shown that regeneration of dorsal root ganglion central processes into a peripheral nerve graft and regeneration of dorsal column fibers into a spinal cord lesion site is significantly improved by performing a peripheral nerve lesion. Thus, a preconditioning nerve lesion seems to increase the intrinsic regenerative ability of central axons by enhancing endogenous repair processes, such as elevation of intracellular cyclic adenosine monophosphate that allow axons to overcome myelin inhibition or by promoting of neuronal survival through attenuation of several injury-inducing mechanisms such as excitotoxicity, ion/pH imbalance, oxidative stress, metabolic dysfunction, and inflammation. ${ }^{42-44}$

Another explanation for the good recovery of diabetic patients may originate from the improvements in their glycemic control; they received appropriate follow-up and treatment after their release from the hospital. Even short-term improvements in glycemic control have been reported to have an independent, 
additive, and durable effect on the restoration of nerve function in patients with mild to moderate diabetic sensorimotor polyneuropathy. ${ }^{12}$ Apart from the above explanations, the possibility of a type II error due to the small population of this study and the fact that the Bell palsy resolved in a great majority of patients needs to be acknowledged.

Conclusively, HbA1c values seem to be significantly correlated with severe Bell palsy. Nevertheless, it is noteworthy that patients with abnormal $\mathrm{HbA1c}$ values do not seem to be of worse prognosis at the 6-month follow-up visit and seem to fully recover as frequently as patients with normal HbA1c values. Hypertension and hypercholesterolemia, however, do not seem to be correlated either with the severity of Bell palsy or with the degree of recovery 6 months later. The results of this study provide some additional information about the challenging pathophysiology of a peripheral nerve being entrapped in a bony canal. These findings seem to have important clinical implications regarding the diagnosis of Bell palsy, as well as the consultation of diabetic patients about both treatment and prognosis. First, they may imply that serum glucose, especially HbA1c levels, are indispensable parameters in the diagnostic procedure of Bell palsy. Second, they further highlight the importance of glycemic control for the prevention as well as the treatment of peripheral neuropathies in diabetic patients. Finally, they seem to provide encouraging prognostic evidence for diabetic patients with Bell palsy. Because Bell palsy often presents as quite a disfiguring situation for diabetic patients, the consultation of these patients and the good prognostic odds that an efficient glycemic control may prove to be quite important in every day clinical practice.

\section{References}

1. Bibas T, Jiang D, Gleeson J. Disorders of the facial nerve. In: Gleeson M (ed). Scott-Brown's Otorhinolaryngology Head and Neck Surgery. 7th ed. London: Edward Arnold Ltd; 2008: 3883-6.

2. Engström M, Thuomas K-Å, Naeser P, Stelberg E, Jonsson L. Facial nerve enhancement in Bell's palsy demonstrated by different gadolinium-enhanced magnetic resonance imaging techniques. Arch Otolaryngol Head Neck Surg 1993;119:221-5.

3. Gilden DH. Bell's palsy. N Engl J Med 2004;351: 1323-31.

4. Smith IM, Heath JP, Murray JA, Cull RE. Idiopathic facial (Bell's) palsy: a clinical survey of prognostic factors. Clin Otolaryngol Allied Sci 1988;13:17-23.

5. Hsieh RL, Wu CW, Wang LY, Lee WC. Correlates of degree of nerve involvement in early Bell's palsy. BMC Neurol 2009;9:22.

6. Abraham-Inpinjin L, Deveries PP. Hypertension and diabetes mellitus in Bell's palsy. In: Graham MD, House WF (eds). Disorders of the facial nerve. New York: Raven Press; 1982: 251-4.

7. Takahashi A, Sobue I. Concurrence of facial paralysis and diabetes mellitus: prevalence, clinical features and prednisolone treatment. In: Goto Y, Horiuchi A, Kogure K (eds). Diabetic Neuropathy. Amsterdam: Experta Medica; 1982: 173.

8. Kahlon AS, Pathak R. Patterns of glycemic control using glycosylated hemoglobin in diabetics. J Pharm Bioallied Sci 2011;3:324-8.

9. House JW, Backmann DE. Facial nerve grading system. Otolaryngol Head Neck Surg 1985;93:146-7.

10. Report of the Expert Committee on the Diagnosis and Classification of Diabetes Mellitus. Diabetes Care 1997;20:1183-1197.

11. Droumaguet C, Balkau B, Simon D, et al. Use of $\mathrm{HBa} 1 \mathrm{c}$ in predicting progression to diabetes in French men and women. Data from an Epidemiological Study on the Insulin Resistance Syndrome (DESIR). Diabetes Care. 2006;29:1619-25.

12. Perkins BA, Dholasania A, Buchanan RA, Bril V. Short-term metabolic change is associated with improvement in measures of diabetic neuropathy: a 1-year placebo cohort analysis. Diabet Med 2010;27: 1271-9.

13. Martinez A. Diabetic neuropathy. Topography, general electrophysiologic features, effect of ischemia on nerve evoked potential and frequency of the entrapment neuropathy. Electromyogr Clin Neurophysiol 1986;26:283-95.

14. Stamboulis E, Vassilopoulos D, Kalfakis N. Symptomatic focal mononeuropathies in diabetic patients: increased or not? J Neurol 2005;252:448-52.

15. Thomas PK, Tomlinson D. Diabetic and hypoglycemic neuropathy. In: Dyck P, Thomas PK, Asbury A, et al (eds). Diabetic Neuropathy. 3rd edition. Philadelphia: Saunders WB; 1993: 1219-50.

16. Gilden DH. Clinical practice. Bell's palsy. N Engl J Med 2004;351:1323-31.

17. Morris AM, Deeks SL, Hill MD, et al. Annualized incidence and spectrum of illness from an outbreak investigation of Bell's palsy. Neuroepidemiology 2002;21:255-61.

18. Bosco D, Plastino M, Bosco F, et al. Bell's palsy: a manifestation of prediabetes? Acta Neurol Scand 2011;123:68-72.

19. Kudoh A, Ebina E, Kudo H, Matsuki A. Delayed recovery of patients with Bell's palsy complicated by non-insulin-dependent diabetes mellitus and hypertension. Eur Arch Otorhinolaryngol 1998; 255:166-7. 
20. de Vegt F, Dekker JM, Jager A, et al. Relation of impaired fasting and postload glucose with incident type 2 diabetes in a Dutch population: the Hoorn Study. JAMA 2001;285:2109-13.

21. Ko GT, Chan JC, Woo J, et al. The reproducibility and usefulness of the oral glucose tolerance test in screening for diabetes and other cardiovascular risk factors. Ann Clin Biochem 1998;35:62-7.

22. Rohlfing CL, Wiedmeyer HM, Little RR, England JD, Tennill A, Goldstein DE. Defining the relationship between plasma glucose and HbA1c: analysis of glucose profiles and HbA1c in the Diabetes Control and Complications Trial. Diabetes Care 2002;25: 275-8.

23. Simon D, Senan C, Garnier P, Saint-Paul M, Papoz L. Epidemiological features of glycated haemoglobin Alc-distribution in a healthy population: the Telecom Study. Diabetologia 1989;32:864-9.

24. Woerle HJ, Pimenta WP, Meyer C, et al. Diagnostic and therapeutic implications of relationships between fasting, 2-hour postchallenge plasma glucose and hemoglobin A1c values. Arch Intern Med 2004; 164:1627-32.

25. Barr RG, Nathan DM, Meigs JB, Singer DE. Tests of glycemia for the diagnosis of type 2 diabetes mellitus. Ann Intern Med 2002;137:263-72.

26. Rohlfing C, Wiedmeyer HM, Little R, et al. Biological variation of glycohemoglobin. Clin Chem 2002; 48:1116-8.

27. Fisch U. Surgery for Bell's palsy. Arch Otolaryngol 1981;107:1.

28. Schwaber MK, Larson TC III, Zealear DL, Creasy J. Gadolinium-enhanced magnetic resonance imaging in Bell's palsy. Laryngoscope 1990;100:1264-9.

29. Tien R, Dillon WP, Jackler RK. Contrast-enhanced MR imaging of the facial nerve in 11 patients with Bell's palsy. AJR Am J Roentgenol 1990;155:573-9.

30. Engström M, Berg T, Stjernquist-Desatnik A, et al. Prednisolone and valaciclovir in Bell's palsy: a randomised, double-blind, placebo-controlled, multicentre trial. Lancet Neurol 2008;7:993-1000.

31. Teunissen LL, Notermans NC, Wokke JHJ. Relationship between ischemia and neuropathy. Eur Neurol 2000;44:1-7.

32. Tesfaye S, Harris N, Jakubashi JJ, et al. Impaired blood flow and arterio-venous shunting in human diabetic neuropathy: A novel technique of nerve photography and fluorescein angiography. Diabetologia 1993;36:1266-74.

33. Newrick PG, Wilson AJ, Jakubowski J, Boulton AJ, Ward JD. Sural nerve oxygen tension in diabetes. BMJ (Clin Res Ed) 1986;293:1053-4.

34. Britland ST, Young RJ, Sharma AK, Clarke BF. Relationship of endoneurial capillary abnormalities to type and severity of diabetic polyneuropathy. Diabetes 1990;39:909-13.

35. Giannini C, Dyck PJ. Ultrastructural morphometric abnormalities of sural nerve endoneurial microvessels in diabetes mellitus. Ann Neurol 1994; 36:408-15.

36. Malik RA, Tesfays S, Thompson SD, et al. Endoneurial localisation of microvascular damage in human diabetic neuropathy. Diabetologia 1993;36: 454-9.

37. Sugimoto K, Shoji M, Yasujima M, Suda T, Yagihashi S. Peripheral nerve endoneurial microangiopathy and necrosis in rats with insulinoma. Acta Neuropathol 2004;108:503-14.

38. Singleton JR, Smith AG, Russel JW. Microvascular complications of impaired glucose tolerance. Diabetes 2003;52:2867-73.

39. Russell J, Sullivan K, Windebank A, Hermann DN, Feldman EL. Neurons undergo apoptosis in animal and cell culture models of diabetes. Neurobiol Dis 1999;6:347-63.

40. McQuarrie IG, Grafstein B. Axon outgrowth enhanced by a previous nerve injury. Arch Neurol 1973;29:53-5.

41. McQuarrie IG, Grafstein B, Gershon MD. Axonal regeneration in the rat sciatic nerve: effect of a conditioning lesion and of dbcAMP. Brain Res 1977; 132:44353.

42. Neumann S, Woolf CJ. Regeneration of dorsal column fibers into and beyond the lesion site following adult spinal cord injury. Neuron 1999;23:83-91.

43. Oudega M, Varon S, Hagg T. Regeneration of adult rat sensory axons into intraspinal nerve grafts: promoting effects of conditioning lesion and graft predegeneration. Exp Neurol 1994;129:194-206.

44. Neumann S, Bradke F, Tessier-Lavigne M, Basbaum AI. Regeneration of sensory axons within the injured spinal cord induced by intraganglionic cAMP elevation. Neuron 2002;34:885-93. 